\title{
O Contestado na sala de aula
}

\author{
Paulo Pinheiro Machado*
}

Palavras-chave

Movimento do Contestado

Ensino de História

Brasil Republicano

Keywords:

Contestado Movement

History Teaching

Republican Brazil.
Resumo: Este artigo analisa as dificuldades de comunicação entre a produção acadêmica e o ensino do movimento social do Contestado. É identificada a necessidade de construção de mediações, de combate a preconceitos, de afirmação de valores positivos de trajetórias populares, além da importância do meio acadêmico aprender com as experiências dos professores do Ensino Fundamental.

Abstract: This paper analyzes the difficulties of communication between academic research and the teaching of social movement Contestado. It identified the need to build mediations, fighting prejudice, affirmation of positive valuesof popular leaders and the importance of academic learning from the experiences of elementary school teachers.

Recebido em $1^{\circ}$ de novembro de 2016. Aprovado em $1^{\circ}$ de março de 2017.

Nas últimas três décadas, o trabalho de pesquisa tem feito avançar o conhecimento sobre o movimento do Contestado em muitos campos, tanto por autodidatas como por integrantes do meio acadêmico mais especializado. ${ }^{1}$ Foram empregados novos acervos documentais, revisadas e reanalisadas antigas fontes, novas perguntas foram lançadas sobre o passado. $\mathrm{E}$ isso resultou em uma série de novas conexões, procurando uma mútua inteligibilidade entre o passado e o presente, refletindo sobre a permanência - nos dias de hoje - de estruturas sociais, econômicas e culturais excludentes, de meios de reprodução de desigualdades. Alguns mitos historiográficos foram superados. São dezenas de teses e dissertações, nas áreas de História, Literatura, Geografia, Antropologia, Sociologia, Educação e até em Ciências Sociais Aplicadas, como Direito e Serviço Social, que repensam as experiências vividas há mais de 100 anos pelos sertanejos do Contestado².

No entanto, como outras áreas de avanço do conhecimento historiográfico, há um descompasso entre a produção acadêmica e o domínio da sociedade sobre este tema. Esse descompasso ocorre nas políticas públicas de memória e no ensino de História predominante nas redes de Ensino Fundamental.
Não é reduzido o número de pessoas, mesmo com formação universitária, que jamais ouviram falar sobre o movimento do Contestado. Entre os que possuem alguma informação, é muito comum a afirmação de que "foi um segundo Canudos, com fanáticos e ignorantes". Há outros que apenas se contentam em defender um "heroísmo" do Contestado, como uma jornada épica de nossos antepassados, sem definir claramente pelo que aquelas pessoas estavam lutando. Como qualquer movimento social de grande envergadura, que resultou em conflito de grandes proporções, o Contestado é um repositório de experiências populares e serve para refletirmos as relações entre o povo pobre, as elites e o Estado no Brasil.

Agora é hora de procurarmos um novo tipo de divulgação que é nossa responsabilidade, como historiadores e pesquisadores. Como traduzir ao grande público escolar as últimas reflexões e contribuições sobre o movimento sertanejo do Contestado?

Precisamos seguir os conselhos do mestre Marc Bloch (1996) que defendia que os historiadores deveriam "saber falar aos doutos e aos escolares" indistintamente ${ }^{3}$. Não devemos e não podemos ficar restritos ao meio acadêmico mais especializado se nossos professores e nossos

* Professor do Departamento de História da Universidade Federal de Santa Catarina, bolsista em Produtividade de Pesquisa II do Conselho Nacional de Desenvolvimento Científico e Tecnológico (CNPQ). E-mail: paulo.pinheiro.machado@ufsc.br. 
livros didáticos continuam trabalhando com muitas limitações sobre esse tema nas redes escolares de Ensino Fundamental. Por mais abundante que seja a historiografia, e mais numerosas as teses e dissertações e monografias sobre o movimento do Contestado, essa temática não ganhará o grande público se não construir parâmetros inovadores para a formação de docentes e produção de material didático à altura deste desafio.

Os trabalhos de Rogério Rosa Rodrigues (2000, 2008, 2016) e de Karoline Fin (2016) são esclarecedores quanto ao estado do material didático e paradidático com foco na Guerra do Contestado, disponível para a rede escolar e, em sua maioria, distribuído pela Secretaria Estadual de Educação e pelas Secretarias Municipais. Trata-se de um material que frequentemente repete os preconceitos da antiga historiografia e da crônica militar sobre os sertanejos, sendo desqualificados como "fanáticos", "jagunços" e "ignorantes". Igualmente grave é a apropriação oficial da memória do Contestado por órgãos estaduais e municipais ligados ao turismo que, ao mesmo tempo em que exalta certo "heroísmo" dos sertanejos, aplaude a construção de uma sociedade de imigrantes e pequenos agricultores de origem europeia, como a "consequência" do conflito, naturalizando a subalterização da população cabocla e fazendo apologia de uma "modernização" que perpetuou desigualdades. ${ }^{4}$

Muitas vezes, o descompasso da produção acadêmica com o ensino tem origem em obras gerais de autores consagrados no meio acadêmico, muito influentes na formação de professores. Essas obras gerais tendem a generalizar movimentos, apontados como episódios secundários e marginais da narrativa central, frequentemente focada na política institucional e no mundo urbano das capitais. Este é o caso de Bóris Fausto e sua "História do Brasil", obra originalmente publicada em 1994, com várias reedições. Em um livro de 650 páginas, o autor dedica dois parágrafos para tratar do Contestado, que é relatado como um movimento social que "combina religião com descontentamento social" (FAUSTO, 1994, p. 296). No texto, há incorreções factuais, como a de que os sertanejos rebeldes eram chefiados por um "Coronel". O autor não esconde sua tese central. O conflito social principal na Primeira República estava no meio urbano, no nascente operariado, que lutava por reivindicações "sem cunho religioso". A religiosidade dos movimentos sociais rurais aparece no texto como um arcaísmo. Na mais recente obra de síntese histórica, "Brasil: uma biografia", de Lilia Schwarcz e Heloísa Starling (2015), o movimento do Contestado é apenas citado como um dos muitos movimentos rurais que combinaram "religião com descontentamento social"; mas, ao contrário de Canudos - que possui uma descrição de três páginas, no livro de 694 páginas não há um parágrafo sobre o movimento do Contestado.

Tão importante quanto a inovação e a atualização dos conhecimentos é o processo pedagógico quotidianamente construído pelos professores, que dão sentido e inteligibilidade aos saberes, despertando nas crianças e nos jovens a curiosidade e a motivação para se processar um mais completo caminho de ensino. Este artigo trata dessa busca de diálogo entre a pesquisa e o ensino; no entanto, é um ponto de vista de pesquisador que se coloca nesta reflexão. Certamente especialistas da área do Ensino de História terão instrumentos mais qualificados para contribuir com este debate.

O estudo da História é fundamental para a formação democrática e cidadã. Não há como se construir um projeto de sociedade minimamente democrática sem o reconhecimento e a construção de sujeitos sociais populares, sem considerar as experiências de luta pela vida e pela melhoria das condições sociais de existência por parte da população. A educação precisa construir um quadro de referência que orgulhe o povo brasileiro de seu passado de lutas e conquistas, e que suas derrotas possam ser avaliadas em um contexto amplo de construção do futuro e combate ao status $q u o$. Não é diferente o caminho que nossos colegas estudiosos da escravidão africana e indígena na produção de novos materiais e na formação de docentes conscientes na compreensão da agência de africanos e indígenas, de formas de luta, resistência e construções culturais que marcam as experiências destas camadas populares. 
Admitir esta agência não é deixar de reconhecer revezes, derrotas populares, vitórias da elite dominante. Significa poder recuperar os contextos complexos de disputa, a indeterminação e a capacidade de invenção e criação das pessoas, mesmo em condições adversas. Portanto, o investimento deve ser focado na construção de uma história de sujeitos, não de vítimas, mas de homens e mulheres de carne e osso que continuam lutando por uma vida melhor.

Dessa forma, consideramos que alguns parâmetros e balizas para a formação de professores e de material didático sobre o movimento do Contestado, devem considerar:

1. A necessidade de entender o projeto modernizador republicano do final do século XIX e início do século XX como um processo excludente dos elementos nacionais, com base em princípios racistas de branqueamento e europeização. A modernização foi uma experiência fundamentada na exploração e na exclusão, uma crítica ao discurso republicano de "progresso" deve ser o ponto de partida para o entendimento da conjuntura brasileira do início do século XX. O Contestado pode ser uma espécie de introdução ao estudo do Brasil Republicano, por dizer respeito a um conjunto de instituições políticas e sociais que tiveram atuação de destaque no conflito, que se modificaram e se consolidaram em posições de destaque político e mando, como a Igreja, o Exército e o poder local dos Coronéis.

2. O Contestado não pode ser visto como um acontecimento à parte, isolado, da história brasileira em geral. Deve ser considerado como a manifestação de uma expressão cultural que ocorreu em outras concentrações camponesas, sendo a tradição de João Maria um forte polo de realização de projetos autônomos que foram alvo do ataque das forças oficiais, desde Santa Maria/RS (1948-1949), o Canudinho de Lages/SC (1897), o movimento dos monges do Pinheirinho (Encantado/RS,
1902) e posteriores à Guerra do Contestado, como o movimento de Bonifácio Papudo (Mafra/SC, 1921), de Fabrício das Neves (Concórdia/SC, 1924-1925), dos Monges Barbudos (Soledade/RS, 1935-1938) e do Timbó Grande/SC (Movimento dos Alonsos, 1942) $)^{5}$.

3. Em um sentido muito mais amplo, mas importante para a reflexão educacional, a experiência das comunidades e "Cidades Santas" do Contestado se comunica diacronicamente ao passado com a experiência jesuítica missioneira e ao presente, com a experiência dos assentamentos da Reforma Agrária. A formação das "cidades santas" e sua disposição urbanística são um ponto de partida dessas comparações, a busca de uma construção de uma sociedade baseada na igualdade e na solidariedade (apesar das adversidades oferecidas pela sociedade circundante) são pontos em comum. O importante é colocar em marcha um processo de mútua inteligibilidade entre $o$ presente e o passado.

4. A sequência factual do movimento do Contestado é muito extensa e complexa, talvez não seja um bom modelo pensar a experiência do Contestado em sua reconstrução factual para a educação escolar, mas se fixar em momentos cruciais, eleitos pelo pesquisador e educador, que poderia ser sobre a invenção das "Cidades Santas", a criação de instituições caboclas como as "formas" e o grupo dos "Pares de França". Uma educação escolar não é o resumo de um estudo acadêmico, precisa ser uma mediação entre a produção acadêmica e os objetivos educacionais para cada ano escolar. Não há, a rigor, diferenças entre as crianças e os jovens da região do Contestado e dos jovens de outras partes do Brasil. O desafio educacional do Contestado não é diferente para os grupos mencionados. Claro que, em circunstâncias específicas, como memórias familiares e experiências locais com o território, um trabalho de ensino sobre o movimento do Contestado 
tem muitas condições mais favoráveis para se desenvolver entre as populações do território do conflito.

5. Se conseguimos nos identificar com as histórias de Zumbi dos Palmares, de Tiradentes, de Antônio Conselheiro, do marinheiro João Cândido, também podemos construir uma identificação positiva com os sertanejos do Contestado. Não se trata de idealização de personagens como indivíduos isolados de seu contexto; porém, recuperar a história do movimento caboclo significa trazer novamente à tona as experiências de sujeitos históricos relevantes, como os monges João Maria e José Maria, as virgens Teodora e Maria Rosa, os comandantes Chiquinho Alonso, Aleixo, Tavares e Adeodato Ramos, pessoas que ousaram desafiar a ordem vigente e que colocaram suas vidas a serviço dos sonhos e das esperanças de seus amigos e companheiros.

6. É fundamental a necessidade de crítica à historiografia da imigração, à apologia acrítica de fundo étnico, que reproduz "epopeias" de braços modernizadores que desqualificam todo o aprendizado que estes mesmos imigrantes receberam de populações indígenas e caboclas. Há uma necessidade de entendimento das trocas culturais entre imigrantes $\mathrm{e}$ população nacional, que frequentemente conviviam nos mesmos espaços. É hora de a literatura da educação abandonar o discurso ideológico das fontes republicanas. Logo, uma reavaliação da experiência da imigração europeia é parte do processo de reflexão sobre o papel do Contestado no ensino.

7. A abordagem sobre o Contestado não é um capítulo a mais a ser inserido nos livros didáticos, ela significa uma modificação no trato de outros temas conexos. O estudo do movimento do Contestado permite um novo olhar sobre a história do povoamento, do meio ambiente, dos transportes, da economia e de uma série de conexões interdisciplinares. $\mathrm{O}$ estudo do movimento do Contestado é ocasião importante para refletir sobre o Coronelismo e o papel do capital estrangeiro no início da República.

8. O movimento do Contestado precisa ser entendido como um evento nacional e latino-americano, não como um evento local, circunscrito a uma região. A luta pela terra, a luta antioligárquica, a resistência à ação de empresas multinacionais, a destruição de florestas, o deslocamento compulsório de populações não são eventos locais, são experiências compartilhadas por todo o país e por nossos vizinhos continentais. O Contestado precisa ser entendido como importante episódio da história do Brasil Contemporâneo.

9. O importante relevo que a luta pela terra assumiu ao longo do processo da guerra sertaneja não pode ser ligado automaticamente ao que se entende hoje por luta pela terra. A luta pela terra no Contestado é inseparável da luta de construção do projeto de autonomia das "Cidades Santas", o espaço disputado não é exatamente um espaço de "produção", mas é importante lembrar que os sertanejos consideravam o acesso a terra como espaço "de liberdade".

10. A presença de trabalhadores compulsórios provenientes do norte do Brasil, repetida por décadas por extensa historiografia, já foi desmistificada pela historiografia recente ${ }^{6}$. No entanto, muitas obras continuam a repetir esses equívocos, que são uma forma de explicar a resistência cabocla como parte de um ingrediente "de fora". A presença de imigrantes europeus na construção da estrada de ferro São Paulo - Rio Grande, junto a turmeiros da região foram apontados pela pesquisa mais recente. É necessário se entender as experiências destes trabalhadores estrangeiros como 
turmeiros como parte de seu processo de nacionalização no país, ambientação ao local de trabalho e relação com populações nacionais. Embora o processo econômico capitaneado pela Brazil Railway e pela Lumber and Colonization tenha contribuído para a marginalização das populações nacionais, o movimento do Contestado não possuiu características xenofóbicas, agregando indistintamente nacionais $\mathrm{e}$ imigrantes dentro de seus redutos.

11. Como desdobramento da tese anterior, à medida que populações de origem europeia foram adotando vários aspectos do modo de vida e dos conhecimentos das populações nacionais, não há como se fazer uma definição racial do caboclo, mas sim a definição de alguns parâmetros para uma identidade cultural destes sujeitos. Ser caboclo é adotar um modo de vida ligado à subsistência, a uma itinerância espacial e a um modo de vida desconectado das demandas capitalistas. Embora seja um grupo social que viva em situação de marginalidade no mundo capitalista, os caboclos do Contestado são herdeiros de uma rica visão de mundo de seus antepassados das mais diferentes origens.

12. Há que se tratar com muito cuidado da religiosidade cabocla, suas instituições e o contexto geral do projeto que representaram. Os sertanejos não podem ser apresentados como "fanáticos", "irracionais" ou "loucos", mas sim como pessoas normais que lutavam pelo que acreditavam com os instrumentos culturais que tinham dentro de suas experiências e heranças. Enfrentaram seu desafio de luta com suas crenças, tais como outros brasileiros fizeram em Canudos, na Balaiada, na Cabanagem. Imagens e linguagens ligadas a uma "Santa Religião" e a um processo de renovação e recriação de sociedade são muito mais a realização de um projeto de liberdade que uma simples expressão de um discurso religioso.
13. É preciso evitar afirmações equivocadas sobre o impacto da modernidade em comunidades tidas como "atrasadas", pois apenas reproduzem o discurso das elites republicanas de associar os caboclos à ignorância, às carências. A noção de que os sertanejos ficaram boçalizados com a presença da ferrovia é um equívoco por não entender que esta população tropeira tinha um horizonte social com grande amplitude geográfica, conhecendo já as ferrovias em construção no Rio Grande do Sul, no Paraná, na Argentina e em São Paulo. De igual maneira, é incabível o argumento de que o uso da aviação foi uma inovação do Contestado, visto que ocorreu apenas um pequeno voo fracassado e que o avião não passou de peça de propaganda sobre a modernização do exército. A referência ao uso de equipamentos ditos modernos não passa de curiosidade mórbida sem qualquer significado prático para o desenrolar do conflito ${ }^{7}$.

14. Especial destaque deve ser dado à invenção do "Quadro Santo" ou da "Cidade Santa", o que se justifica pela criação de novo projeto de sociedade defendido pelos sertanejos, suas características comunitárias e anticapitalistas expressamente formuladas. No entanto, o "Quadro Santo" vivia com o recrudescimento de normas de conduta extremamente rígidas, baseadas na autoridade dos homens e dos mais velhos, mesmo quando eram as crianças videntes e mulheres que se colocavam no centro decisório do poder local. Não é um ambiente a ser idealizado, já que relações machistas e de violência de gênero eram recorrentes, tanto nos redutos, como na sociedade circundante. A recuperação de uma experiência social criativa não deve ser idealizada a ponto de encobrir problemas que existem em quaisquer sociedades.

15. O emprego de imagens artísticas, fotografias, animações, audiovisuais, cartoons, músicas, preces, poesia e outros recursos de 
linguagem deve ser norteado pelos objetivos pedagógicos de aproximação das gerações de crianças e jovens da atualidade com vários aspectos da experiência sertaneja do Contestado. Ademais, o material tem de ser pensado em conjunto com professores que atuam com jovens e crianças e precisa ter o desdobramento adequado a diferentes faixas etárias dos primeiros anos até o Ensino Médio. Mas, atenção: a arte também pode, pelo uso de imagens e expressões descontextualizadas, reforçar preconceitos e reproduzir formas de discriminação e subalterização das experiências populares. Por exemplo, alguns quadros do pintor Zumblick retratam os sertanejos como se fossem macacos. No filme "Guerra dos Pelados", de Sylvio Back (1971), o caboclo representado pelo ator Stênio Garcia procura lutar com espada de pau contra uma locomotiva ("dragão que solta fumaça pelas ventas"), passando uma ideia de ignorância e ingenuidade, como se fossem atributos natos destas populações. Estas obras não podem ser utilizadas sem pelo menos uma crítica a estes tipos de abordagem. No entanto, as obras artísticas são um campo muito fértil para a educação e para a pesquisa em educação que deve envolver os próprios estudantes em um processo de recriação do espírito e das esperanças de liberdade e bem-estar ousadas pelos caboclos há mais de 100 anos.

As questões anteriormente listadas são apenas um ponto de partida de um processo que não pode ter uma receita única e não deve se concluir em um "manual". Como processo educativo, implica um conjunto de princípios, conhecimentos e preocupações a ser manejado e construído pelo professor em sala de aula, para que o mundo acadêmico também aprenda como conversar e como se fazer entender pelo público em geral. Independentemente dos conteúdos trabalhados, o professor precisa atingir os corações dos jovens para a memória e a história do Contestado, como parte da história de sua própria nação.

\section{Notas}

1 Diferentemente de "Guerra do Contestado", que é uma denominação que ressalta os conflitos e combates bélicos entre os sertanejos e as forças oficiais, do Exército, dos Regimentos de Segurança do Paraná e Santa Catarina, optamos aqui por ressaltar a experiência sertaneja dos "quadros santos" ou "cidades santas", já que se trata de um processo social e cultural muito mais rico e complexo. Daí nossa opção por focar no "movimento do Contestado" ou no "movimento sertanejo do Contestado". De igual maneira, como a maior parte do movimento ocorreu em território catarinense oficialmente não contestado pelo Paraná, quando referimos a "região do Contestado" estamos considerando os territórios onde se construíram as "cidades santas", ou seja, algo como hoje se denominam as regiões do Meio Oeste e Planalto Catarinense

2 A renovação historiográfica - e de estudos na área das ciências humanas em geral - começa com o sociólogo Duglas Teixeira Monteiro (1974), quem primeiro defendeu que os sertanejos do contestado eram "pessoas normais", e tem sequência com Nilson Thomé (1982), com a pedagoga Marli Auras (1983), Ivone Gallo (1996), Delmir Valentini $(1999,2009)$, Paulo Pinheiro Machado (2004), Márcia Janete Espig (2008, 2012), Rogério Rosa Rodrigues (2000, 2008), Susan Aparecida de Oliveira com sua tese de doutorado em Literatura (2006), com a antropóloga Tânia Welter (2007), Alexandre Assis Tomporoski $(2007,2013)$, no trabalho de Alexandre de Oliveira Karsburg (2012).

3 Na obra Apologia da História ou o Ofício do Historiador.

4 Uma crítica mais sistemática às obras didáticas disponíveis sobre o Contestado, podemos ver em: Rodrigues, 2016 e em Fin, 2016

5 Essas concentrações camponesas ocorridas em nome do Profeta João Maria, com ou sem sua presença, são estudadas por: Ferri, 1974; Martins, 2007; Karsburg, 2012; Kujawa, 2001 e Machado, 2008.

6 Márcia Janete Espig faz uma completa e mais atualizada análise sobre a origem dos trabalhadores que construíram a Estrada de ferro São Paulo - Rio Grande, Personagens do Contestado: os turmeiros da EFSPRG. Ao contrário do que consta no Relatório do General Setembrino de Carvalho, que é reproduzido por Oswaldo Cabral, obra que afirma que grande número de trabalhadores do nordeste do Brasil foram compulsoriamente destinados à construção da Estrada de ferro São Paulo - Rio Grande, Espig vai direto à documentação do período e identifica a presença de turmeiros da região e de origem imigrante.

7 Embora a obra de Maurício Vinhas de Queiroz (1966) ainda seja a mais completa pesquisa empírica sobre o movimento caboclo, sua visão sobre a "anomia" vivida como um "autismo patológico" dos sertanejos reproduz um preconceito da sociologia da época, que frequentemente caía na simplificação do "moderno" versus "arcaico", tal como fez Maria Isaura Pereira de Queiroz. 


\section{Referências}

AURAS, M. Guerra do Contestado: a organização da Irmandade Cabocla. Florianópolis: Editora da UFSC, 1983.

A GUERRA dos Pelados. Direção: Sylvio Back. Roteiro: Sylvio Back, Guido Wilmar Sassi. Intérpretes: Átila Iório, Jofre Soares, Stênio Garcia, Otávio Augusto, Zózimo Bulbul. 1 DVD (98 min), son., color. Brasil, 1970.

BLOCH, M. Apologia da História ou o Ofício do Historiador. Rio de Janeiro: Jorge Zahar, 2001.

ESPIG, M. J. A presença da Gesta Carolíngea e o movimento do Contestado. Canoas: Ulbra, 2008.

Personagens do Contestado: os turmeiros da EFSPRG. Pelotas: UFPel, 2012.

FAUSTO, B. História do Brasil. São Paulo: USP, 1994.

FERRI, G. Os Monges do Pinheirinho. Porto Alegre: Editora Movimento, 1974.

FIN, K. As mulheres do Contestado: uma abordagem sobre a Guerra do Contestado através da literatura infantil. 2016. 00 f. Dissertação (Mestrado Profissional em Ensino de História) - Programa de Pós-Graduação em História, Universidade do Estado de Santa Catarina, Florianópolis, 2016.

GALLO, I. O Contestado: o sonho do milênio igualitário. Campinas: UNICAMP, 1996.

KARSBURG, A. de O. O Eremita das Américas: a odisseia de um peregrino italiano pelas Américas. Santa Maria: UFSM, 2015.

KUJAWA, H. A. Cultura e religiosidade cabocla. O movimento dos monges barbudos. Passo Fundo: UPF, 2001.

MACHADO, P. P. Lideranças do Contestado: a formação e a atuação das chefias caboclas (19121916). Campinas: UNICAMP, 2004.
. O conflito do Canudinho de Lages (1897).

Revista de Estudos de Sociologia, v. 13, n. 24, p. 1-14, 2008.

MARTINS, C. da S. O Mato do Tigre e o Campo do Gato: José Maria e o combate do Irani. Florianópolis: Insular, 2007.

MONTEIRO, D. T. Os errantes do novo século. São Paulo: Duas Cidades, 1974.

OLIVEIRA, S. A. de. Guerra do Contestado: mímesis e políticas da memória. 2006. 00 f. Tese (Doutorado em Literatura) - Programa de PósGraduação em Literatura, Universidade Federal de Santa Catarina, Florianópolis, 2006.

RODRIGUES, R. R. Os sertões catarinenses: embates e conflitos envolvendo a atuação militar na Guerra do Contestado. 2000. 00 f. Dissertação (Mestrado em História) - Programa de PósGraduação em História, Universidade Federal de Santa Catarina, Florianópolis, 2000.

. Veredas de um grande sertão: a Guerra do Contestado e a modernização do Exército brasileiro na Primeira República. 2008. 00 f. Tese (Doutorado em História), Programa de Pós-Graduação em História, Universidade Federal do Rio de Janeiro, Rio de Janeiro, 2008.

. "Nas águas do esquecimento: o movimento do Contestado e o dever de memória". In: PRIORI, A.; GRUNER, C. (Org.) Contestado: 100 anos de uma guerra sem fim. Movimentos e conflitos sociais no sul do Brasil. Estudos sobre Santa Catarina e Paraná (séculos XIX e XX). Curitiba: ANPUH-PR, 2016. p. 29-53.

SCHWARCZ, L.; STARLING, H. Brasil: uma Biografia. São Paulo: Cia das Letras, 2015.

THOMÉ, N. O trem de Ferro: a ferrovia do Contestado. Florianópolis: Lunardelli, 1982.

TOMPOROSKI, A. A. O Pessoal da Lumber: Um estudo acerca dos trabalhadores da Southern Brazil Lumberand Colonization Company e sua 
atuação no planalto norte de Santa Catarina, 1910-1940. 2007. 00 f. Dissertação (Mestrado em História) - Programa de Pós-Graduação em História, Universidade Federal de Santa Catarina, Florianópolis, UFSC, 2007.

VALENTINI, D. Da cidade Santa à Corte Celeste. Florianópolis: Insular, 1999.

O polvo e seus tentáculos: A Southern Brazil Lumberand Colonization Company e as transformações impingidas ao planalto contestado, 1910-1940. 2013. 00 f. Tese (Doutorado em História) - Programa de Pós-Graduação em História, Universidade Federal de Santa Catarina, Florianópolis, UFSC, 2013.

Atividades da Brazil Railway Company no Sul do Brasil. 2009. 00 f. Tese (Doutorado em História) - Programa de Pós-Graduação em História, Pontifíca Universidade Católica, Porto Alegre, 2009.

VINHAS DE QUEIROZ, M. Messianismo e Conflito Social: a Guerra Sertaneja do Contestado, 1912-1916. Rio de Janeiro: Civilização Brasileira, 1966.

WELTER, T. O Profeta São João Maria continua encantando no meio do povo. Um estudo sobre os discursos contemporâneos a respeito de João Maria em Santa Catarina. 2007. 00 f. Tese (Doutorado em Antropologia) - Programa de Pós-Graduação em Antropologia, Universidade Federal de Santa Catarina, Florianópolis, UFSC, 2007. 